\title{
The Important Influence of Religions Belief on the Development of Sibe Ethnic in Xinjiang
}

\author{
Yanzhen Huang \\ Shaanxi Xueqian Normal University, Xi'an 710000, China.
}

\begin{abstract}
The Sibe tribe is one of the ancient tribes of the Northeast China, but because of some historical reasons, it divided into the Northeast Sibe and Xinjiang Sibe now. And the Xinjiang Sibe population accounted for $30 \%$ of the total. In order to explore the Sibe ethnic in Xinjiang in the process of development is how to maintain the independence from other national annexation, and developed into an independent ethnic from the Manchu tribe. This paper focus on research the important role of religion in Xinjiang Sibe ethnic in the process of development. Finally found that Sibe ethnic tolerance of foreign religions and loyalty to traditional beliefs jointly promote their development at the same time to maintain their own national cohesion and independence. And the influence of religion on politics, economy and culture is very great.
\end{abstract}

Keywords: Religions belief; Sibe ethnic in Xinjiang; important influence.

\section{Background}

The development of a nation can not be separated from its cultural, economic, religious beliefs and so on. In the history of the world, religion has always played a definite role in the development of the country. Therefore, it is necessary to study the history of religious belief to thorough understanding the history of the development of a nation.

Since ancient times, China is a multi-ethnic country, each nation has its own unique culture and history. Throughout the history of those ethnics, the Sibe is very unique. Because it was only a small tribe attached to the Manchu, but it did not disappear as the other tribes, but became an independent ethnics today. In the process of development is not the other big national annexation and always maintain its own tribal independence, eventually become an independent ethnic. Religious belief plays a very big role in it.

\section{The Brief history of Xinjiang Sibe Ethnic Development}

The Sibe ethnic is an ancient tribe of Northeast China, the origin of its name has not been determined yet. But it is certain that in the late Yuan Dynasty and early Ming Dynasty when the Sibe ethnic as one of the three tribes in Mongolia have been recorded[1]. There are several important turning point in the development of Sibe after record as shown in Figure 1.

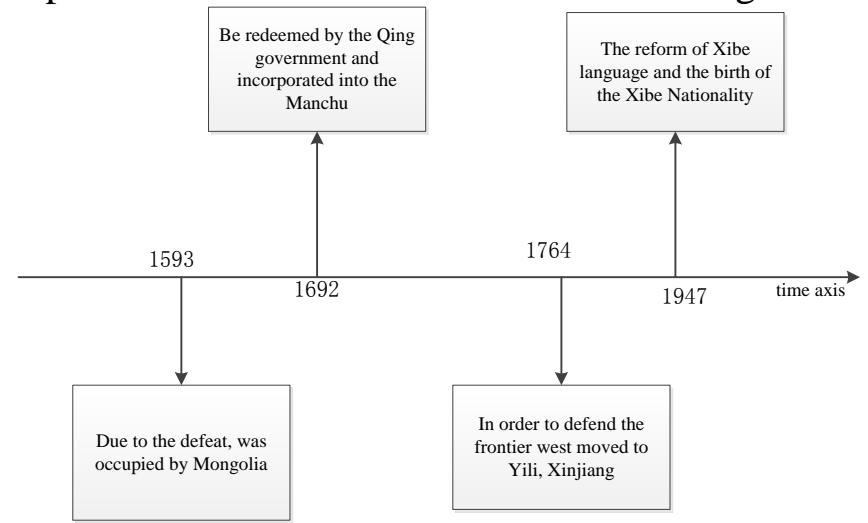

Figure 1 Important turning point in the history of the development of Sibe ethnic

In 1593, as a result of the defeat, Sibe tribe occupied by Mongolia Department. Until 1692, the Qing government to spend lots of money to redemption of the Sibe ethnic from Mongolia and incorporated into the Manchu. In 1764, in order to defend the motherland frontier, thousands of Sibe 
generals from Shenyang to Xinjiang, began more than 170 years of guarding the frontier life. These Sibe people come from Shenyang built the camp and farming in Xinjiang, when the new China was founded, it was transformed from a tribe to an independent ethnic[2]. Figure 2 shows the four stages of development of Sibe people in Xinjiang.

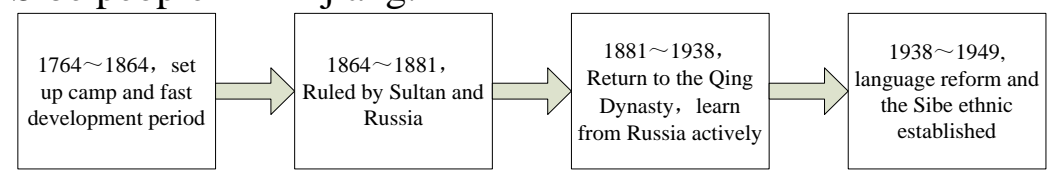

Figure 2 the four stages of development of Sibe people in Xinjiang

The first one hundred years of the Sibe people in Xinjiang is their rapid development period. In these one hundred years, they not only quickly grow their own army, but also win more than ten times the war for the country. Between 1864 and 1881, Sibe tribe occupied by Sultan and Russian, the camp also canceled. Until 1881, the tribe belongs to the Qing Dynasty again, at this time they began to actively learn from the advanced culture of Russia. This stage is the foundation of Sibe tribe from advocating force to advocating literary transformation. In 1912, the Qing Dynasty perished, but the Sibe camp in Xinjiang was officially banned until 1938. From 1938 to 1949 is the Xinjiang Sibe tribal important period of reform, in the meantime, advanced youths to reform the Sibe language and text, and eventually became an independent ethnic[3].

\section{Religion Development of Xinjiang Sibe Ethnic}

Xinjiang Sibe ethnic's religion history is very characteristic due to the changes of its historical evolution and the living area. With the passage of time and the change of living area, some new religions continue to join the Sibe faith, as shown in Figure 3.

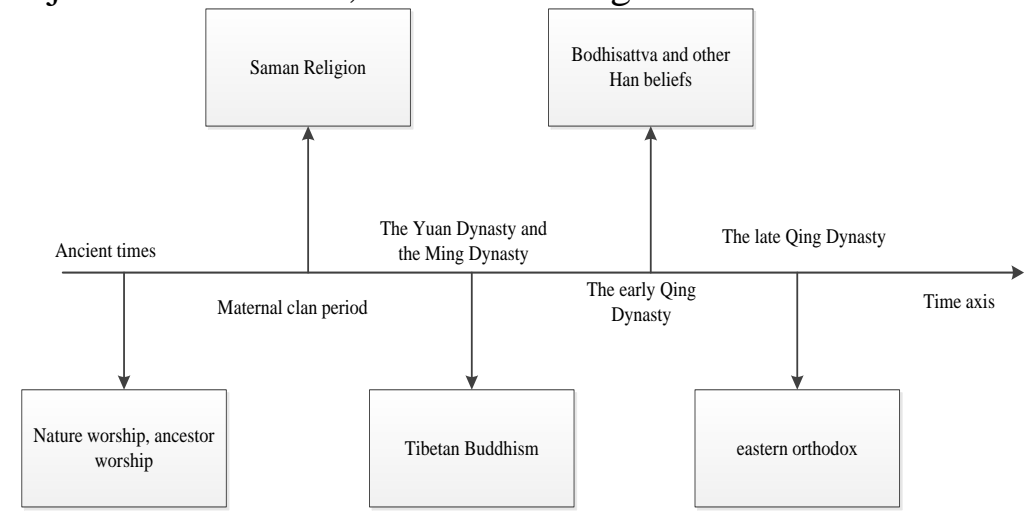

Figure 3 some religious beliefs of the Sibe ethnic

Since ancient times,Sibe people are animists. Sibe nature worship and ancestor worship in the ancient times and the Shaman in the maternal period are both based on animism ideology. To the Yuan and Ming Dynasty, Tibetan Buddhism began to enter the Sibe tribe's spiritual world. After being redeemed by the Qing government, Han nationality belief has gradually entered the field of belief. After the West moved to Xinjiang, in addition to reserves the Shaman, Tibetan Buddhism and Guan Gong, Bodhisattva and so on, the Russian Orthodox Church has entered a number of Sibe family[4].

The Shaman and Tibetan Buddhism is a relatively large impact on its development. Shaman is one of the longest running belief in human history, it can be traced back to the middle of the Old Stone Age[5]. Shaman once is a primitive religion belief shared by northern nationalities in China. The Sibe people think that human was ill because of their soul was interference by the evil sprite, and the Shaman is the man who can drive away the evil spirits. Shaman to cure people still can be seen in the Sibe people inhabited areas until now, we can see that the Shaman occupies an important position in the Sibe people's life. In the Yuan and Ming Dynasty, the Mongolia aristocracy very exalted Tibetan Buddhism, and the Sibe tribe is ruled by Mongolia at this time. Due to the influence of the Mongolia aristocracy, Sibe people began to believe in Tibetan Buddhism[6]. In 1707, Sibe people raised funds 
to build a Tibetan Buddhist temple in Shenyang, named Taiping temple, also called The Temple of Sibe. Taiping temple is still Sibe people worship place until now.

The Sibe ethnic not only show respect to all kinds of gods, but also very loyal to their clan generation spread Xilimama and so on. So the Sibe belief history showed diverse characteristics

\section{The Important Influence of Religions Belief on the Development of Sibe Ethnic in Xinjiang}

The influence of religious belief on Xinjiang Sibe nationality development in all aspects. This article mainly discusses from three aspects of politics, economy and culture.

a. the influence of religion on its politics

The Sibe tribe is not the only one to Xinjiang to defend the frontier tribes, but it is the only one that has survived and became an independent ethnic. According to historical records, then moved to the West Xinjiang Sibe tribe only 3000 people and it is no more than 50 thousand people until now. So few people end up as a ethnic, mainly by the great national cohesion of the religious belief. Although the Sibe ethnic has been accepted to many foreign religions, but they never give up on their own beliefs. It is this traditional insistence and the inclusion of foreign culture that it is not in the development of other large ethnic annexation.

During the republic of China, the Sibe youth who learning the Russia and the Soviet Union advanced culture reformed the Sibe writing and language in the traditional insistence, the Sibe ethnic establish finally. That is the greatest impact on its politics by Sibe ethnic religious beliefs.

b. the influence of religion on its economy

The influence of religious belief on Xinjiang Sibe ethnic economy is also very important,mainly in the following four aspects:

First, religion has a good effect on the establishment of an orderly economic order. Honesty is the core of the economic system, and Tibetan Buddhism, orthodox all require Christians not to lie. With religious constraints, the market order is very good, so the Sibe ethnic of Xinjiang's economic development is very rapid;

Second, charity in religion is playing a function of redistribution. Most religions advocate sharing, this will help to reduce the gap between rich and poor in society. Reducing the gap between the rich and the poor is conducive to social stability, and the stable society can promote the development of economy;

Third, religious attention to education is conducive to improving the quality of the people, it is good for the long-term economic development. According to statistics, the education level of the Sibe ethnic ranked second in the country, second only to the Chaoxian ethnic. From the Sibe people to Xinjiang until now, their economic level in the Xinjiang area has been at a high level;

Finally, religious consumption is also a kind of stimulation to the social demand. For example , the Sibe people built the Taiping temple in the northeast, after arriving in Xinjiang, they also built many temples. In order to express devotion to God, people often rushed to the temple to worship from all over the area, this process will produce such as travel, accommodation, food and other expenses, promote economic prosperity.

From the above four points, we can see that religion is good for the economic development of Xinjiang Sibe ethnic.

c. the influence of religious belief on its culture

In the history of human development, the influence of religion on culture is very large, Xinjiang Sibe ethnic is no exception. The influence of religious belief on the Xinjiang Sibe culture mainly reflected in the following three aspects.

First, the influence of religious belief on the cause of national education. Although relatively small number of Sibe ethnic in Xinjiang, but people's education is very high, they are said to be a born translator.

Second, the influence of religion on the architectural landscape. Observation of Sibe architecture can be seen clearly on the impact of Buddhism and their worship of the shaman. For example, they would carve a picture of a shaman or Buddha in a house. 
Finally, the influence of religion on national psychology. For example, after the Tibetan Buddhism to enter the Sibe ethnic's spiritual world, they like red and white. This is because Buddhism thinks red can drive away evil and white represents purity.

From the above three points, we can see the cultural influence of religion on Sibe people in many ways. Precisely because of the scope of religious influence is so large, Sibe culture can be preserved so complete.

\section{Conclusion}

Sibe ethnic in China is an ancient tribe originally, but it did not disappear like any other tribe, but developed into an independent ethnic. In order to study the deep reasons in the development of Sibe in Xinjiang, this paper focuses on the important role of religion in this process. After a careful understanding of the history of Xinjiang Sibe ethnic and their religion belief, we found that the impact of religion on Xinjiang Sibe ethnic development is very large, including political, economic, cultural and other aspects. In general, there is a great contribution to the development Xinjiang Sibe ethnic by religion belief.

\section{Acknowledgements}

This work was supported in part by the social science and humanity on Young Fund of the ministry of Education, 14YJC850006.

\section{References}

[1] Wang Changquan. Study on some problems in the early history of Xibo Nationality and Horqin Mongolia relations[D]. National University Of The Inner Mongol,2001.

[2] The writing group of Xibo ethnic History. A brief history of the Xibo ethnic[M]. National Publishing Company.1986.

[3]Wang Congyan. The Xibo moved to the west after the resettlement of Xinjiang[J]. Journal of corps Party School,2013(1):59-62.

[4] Kurban Jean Semti.I come from Xinjiang[M].Zhongxin Publishing Company.2014.

[5] Lv Daji ,He Yaohua, Yu Jinxiu. The integration of primitive religious data of all ethnic groups in China[M]. China Social Science Publishing Company, 2013.

[6] Hu Fangyan. One of the Xinjiang Qapqal Xibo religion history and current situation investigationXibo ethnic Tibetan Buddhism belief[J]. Religious Studies,2010(3):110-117. 